\title{
Escuelas campesinas de agroecología: una estrategia de desarrollo endógeno sustentable en el municipio de Tuluá
}

\author{
Fernando de Jesús Álvarez R. \\ fernando.alvarez@unad.edu.co \\ Universidad Nacional Abierta y a Distancia (UNAD) \\ Escuela de Ciencias Agrarias Pecuarias y del Medio Ambiente (ECAPMA)
}

CEAD Palmira, Colombia

Resumen.- Las Escuelas Campesinas de Agroecología (ECAS), son una estrategia de Desarrollo Endógeno Sustentable (DES) "Para Vivir Bien" en los Andes Tulueños (Valle del Cauca). Este trabajo analiza los enfoques filosóficos, metodológicos y éticos políticos que orientaron la conformación de las ECAS en dos corregimientos del municipio de Tuluá. La metodología de trabajo se enmarcó en la Investigación Acción Participación (IAP) y en el enfoque Histórico Lógico Cultural (HLC). Las ECAS como estrategia de DES se convierten en espacios de resistencia a partir del rescate de la cultura, la historia, el territorio y el cuidado de los bienes naturales; desde la revalorización de los saberes locales y los contenidos históricos que han sido excluidos por el discurso dominante de Occidente. Los campesinos existen porque históricamente han manejo de manera sustentable los bienes naturales.

Palabras clave: Desarrollo Endógeno Sustentable, Investigación-Acción-Participación (IAP), Enfoque Histórico-Lógico-Cultural, Metodología Campesino a Campesino, Sociedad Rural Campesina.

\begin{abstract}
Rural Schools of Agroecology (ECAS) are a strategy of sustainable endogenous development (DES) "To Live Well” in Andes Tulueños (Valle del Cauca). This paper analyzes the philosophical, methodological and ethical-political approaches that guide the formation of the ECAS in two settlements in the municipality of Tuluá. The methodology is framed in Research-Action-Participation (IAP) and the Historic Logical Cultural Approach (HLC). ECAS as a strategy of DES becomes spaces of resistance for the rescue of culture, history, territory and care of natural assets by the revaluation of local knowledge and the historical contents that have been excluded by the dominant discourse of the West. Rural farmers exist because they have historically managed natural assets in a sustainable manner.
\end{abstract}

Keywords: Sustainable Endogenous Development, Research-Action-Participation (IAP), Historic Cultural Logic Focus, Rural Farming Methodology, Rural Peasant Society.

\section{Introducción}

El territorio limitado por la margen derecha del río Cauca y las estribaciones de la cordillera Central -denominado Tuluá- alberga gran diversidad agrobiológica y cultural. Coexisten una gama de ambientes que conforman un complejo mosaico de paisajes y hábitats. Históricamente habitado por grupos indígenas prehispánicos y comunidades campesinas que emergieron en el valle geográfico del río
Cauca en las postrimerías del siglo XVIII y, a finales del siglo XIX en los andes tulueños (Mejía 1996, Valencia \& Londoño 1996). La modernización agrícola empezó con la propuesta tecnificada de la caña de azúcar iniciada a finales del siglo XIX y la fortalecida llegada de La Misión Agrícola Chardón (1929), se transformaron las antiguas haciendas en empresas agroindustriales con el objeto de sacar del atraso el sector agropecuario en que encontraba. 
En las primeras cuatro décadas el sector público del departamento del Valle se interesó en superar el atraso económico regional, con este propósito se contrató la misión Inglesa en 1927 que recomendó impulsar el desarrollo capitalista agrícola en gran escala con innovaciones tecnológicas y el cultivo de algodón. En 1929 la Misión Chardón de Puerto Rico recomendó intensificar el cultivo de caña, la transformación azucarera empleando alta tecnología, y el establecimiento de granjas experimentales (Vásquez, 1996). En la segunda década del siglo XX, la industrialización y los procesos de urbanización generaron la pérdida de la biodiversidad natural y agrícola, la devastación del entorno natural y cultural, y la destrucción de la memoria tradicional representada en los saberes locales acumulados durante miles de años de interacción entre la sociedad humana y la naturaleza (Toledo 2003).

Para llevar a cabo esta planificada labor -de imponer la agricultura industrializada hija legítima de la revolución industrial y el reconocimiento de la ciencia como único modo válido de conocimiento que descalifica cualquier otra forma de conocer el mundo como parte del mecanismo que intenta justificar un sistema de dominación- se crearon los centros de experimentación a cargo de instituciones académicas y se adecuaron los planes de estudio de las Ciencias Agrarias para formar los técnicos que van a reproducir el discurso adecuado a las nuevas necesidades del mercado para controlar la sociedad rural campesina, llamaron atrasados, arcaicos, primitivos, inútiles; los saberes o conocimientos campesinos locales negando sistemáticamente una sabiduría y una cultura construida durante milenios (Toledo 1996a). Las comunidades campesinas tienen una memoria tradicional y un cúmulo de saberes que existen en las mentes de los productores (agricultores, pescadores, ganaderos, cazadores, recolectores) y que han servido durante milenios para que la especie humana se apropie de los bienes y servicios de la naturaleza ayudando a conservar los bienes naturales (Toledo 1996).
Ahora bien, todo lo anterior es la prueba irrefutable de un proceso sistemático de invisibilización de la sociedad rural campesina y de exclusión de los bienes naturales en las políticas de desarrollo rural en el Valle del Cauca y por ende en el municipio bajo la égida del proyecto modernizador iniciado en la década de los 30's en este ubérrimo territorio.

La expansión del proyecto modernizador ha significado la imposición de un modelo económico, político, cultural, conductal, y por supuesto cognoscitivo, a través del cual se han ido expandiendo los valores supuestamente universales de occidente. En la perspectiva epistemológica, la expansión civilizadora se ha traducido en la imposición de una sola forma de conocimiento, que adquiere su modalidad más sofisticada en la ciencia contemporánea.

En este escenario, emergen las Escuelas Campesinas de Agroecología (ECAS), como un enfoque de Desarrollo Endógeno Sustentable en la búsqueda del "Vivir Bien”. En las ECAS se recupera la historia y recrea la cultura; además, se conserva los suelos, las aguas, las plantas y los animales, se cuidan las semillas, se democratiza la producción de alimentos; se recupera el valor de la palabra, se recrea los saberes locales y la memoria tradicional, la solidaridad y la fraternidad (Álvarez 2009). Igualmente, las ECAS surgen para hacer visible la sociedad rural campesina a través de la revalorización de los saberes locales, el cuidado de la agrobiodiversidad, la apropiación del territorio y la custodia de los bienes de la naturaleza (manejo sustentable de los bienes naturales). Esto se concretiza a través del diálogo intra e inter cultural, y transdisciplinar entre el mundo de afuera científico y el mundo de adentro campesino, donde el campesino se convierte en sujeto histórico de su propio desarrollo (COMPAS 2009).

El objetivo de este trabajo fue analizar las experiencias de dos escuelas campesinas de agroecología desde la perspectiva del desarrollo endógeno sustentable como búsqueda 
del "Vivir Bien" en los corregimientos de San Rafael y San Lorenzo, del municipio de Tuluá, Valle del Cauca.

\section{Materiales y métodos}

\section{Investigación participativa revalorizadora}

La investigación se realizó desde una metodología eminentemente participativa lo que ha permitido entender y analizar de manera profunda la realidad de las comunidades campesinas -como sujeto de investigación-, con base en el conocimiento local y con la participación activa de los actores locales en todo el proceso de la investigación por medio del diálogo intra e inter cultural, y multidisciplinar, posibilitando la creación de un ambiente de confianza y mutua comprensión. En tal sentido, se entiende por Investigación Participativa Revalorizadora "al proceso metodológico que tiene el rol de generar conocimientos y/o recrear saberes locales desde la perspectiva de los actores sociales (locales y externos), para la compresión de la realidad (vida material, vida social y vida espiritual), en un determinado contexto espaciotemporal, encaminado hacia la búsqueda de espacios para el desarrollo rural sostenible (San Martín 1997, AGRUCO 1998, Delgado 2005).

\section{Enfoque teórico metodológico: \\ Histórico Cultural Lógico (HCL)}

Este enfoque busca comprender, analizar y estudiar la realidad de las culturas campesinas en espacio-tiempo (pasado, presente y futuro) fundamentado en la interrelación de la vida material, social y espiritual, desde la perspectiva de los actores sociales (San Martín 1997). El enfoque enfatiza la comprensión de la vida real de un contexto tomando en cuenta el aspecto histórico, la vida actual con sus problemas y potencialidades, especialmente la vida rural tal como es (San Martín 1997).

La emergencia de los saberes locales se hace a través del diálogo intra e inter cultural e intercientífico desde la conversación (el relato), es decir, la palabra como espacio de construcción del otro. Se hicieron diez entrevistas semiestructuradas, 14 conversaciones informales, dos grupos de discusión, dos encuentros campesinos, 46 visitas de campo y dos giras agroecológicas; para deslucidar el mundo rural en estudio.

\section{Momentos del proceso de investigación}

\section{Análisis teórico conceptual}

Para entender la propuesta de ECA se utilizó el concepto de Desarrollo Endógeno "Para Vivir Bien”, el método Histórico-Cultural-Lógico, Investigación Acción Participativa (IAP), entre otros. Igualmente se procedió a realizar un acercamiento a las dos comunidades sujeto de estudio, para la aprobación de la propuesta de investigación; esto permitió establecer los lazos de confianza que este tipo de investigación requiere.

\section{Trabajo de campo}

Con este marco conceptual que originó la forma de abordar la propuesta de Escuelas Campesinas se inicia la recolección y registro de los datos en campo y la correspondiente sistematización de la información desde la perspectiva del mundo material, social y espiritual.

\section{Técnicas de investigación}

Las técnicas de investigación que se utilizaron para la recolección de la información cualitativa y que involucran activamente a las comunidades sujeto de estudio como protagonistas de la obtención de la información son: dos estudios de casos, diez entrevistas, dos talleres de discusión, dos historias de vida y dos grupos focales. En todo el proceso investigativo se hizo observación participante.

\section{Validación de la investigación}

Una vez analizados los datos y descrito todo lo concerniente a las ECAS como una estrategia de Desarrollo Endógeno Sustentable en la búsqueda del "Vivir Bien", se pone a consideración de la comunidad el trabajo de investigación para su respectivo proceso de validación, completar la información si se considera pertinente 
y se confirmó la veracidad de la información obtenida en campo.

\section{Tipo de estudio: Exploratorio}

\section{Marco teórico}

Generalidades sobre Las Escuelas Campesinas de Agroecología (ECAS)

Las ECAS emergen en el municipio de Tuluá como respuesta a los modelos de desarrollo rural emanados del Estado y que buscaban una supuesta modernización del campo bajo la égida del mercado y del gran capital, modernización que llevaba consigo beneficiar a la cultura rural empresarial, agroindustrial, narcoterrateniente y terrateniente e implícitamente la exclusión de la sociedad rural campesina por premoderna e improductiva, desconociendo un caudal de conocimientos, saberes y experiencias en el modo de hacer agricultura, ganadería y manejo relativo de los recursos naturales (Toledo 1991), sustentado en centurias de años de relación armónica entre el hombre, la naturaleza y las deidades. Igualmente, la propuesta educativa arrebata la sabiduría de los campesinos cafeteros (San Rafael y San Lorenzo) y entregaba a sus hijos y nietos modelos cargados de las ilusiones mercantilistas del sistema urbano industrial dominante (Castaño 2002).

Las estructuras permanentes de violencia generadas desde espacios políticos de las élites urbano-industriales mercantilistas han auspiciado la muerte y desplazamiento permanente en los espacios de la sociedad rural campesina, unidos a sectores terratenientes o de propietarios ricos. Las diferentes violencias que hemos vivido representan procesos de empobrecimiento cada vez más dramáticos de los campesinos y de enriquecimiento y acumulación de capital de las élites locales que han detentado el poder (Castaño 2002).

La sociedad rural campesina solamente ha sido visible en la guerra, en el desarraigo, en el desplazamiento y en el utilitarismo partidista, cuando requieren de sus votos (Castaño 2002).
No obstante, se hace visible hoy a través de las ECAS; toda vez, que: primero, cuidan los bienes naturales (el aire, el suelo, el agua, la flora, la fauna, los microbios); segundo, guardan las semillas como don único e inestimable de la naturaleza (banco comunitarios de semillas, conuco de crianza o jardines de la vida); tercero, democratiza la producción de alimentos como imperativo en estos tiempos de dictadura alimentaria, en los que un puñado de transnacionales controlan el suministro mundial de alimentos; cuarto, recuperación de la palabra (redes de credibilidad), fraternidad y solidaridad; quinto, revaloriza los saberes locales y recupera el conocimiento sobre la biodiversidad; sexto, es el soporte de la autonomía y la soberanía alimentaría de nuestra región y; séptimo, revalorización de la historia y la cultura local (Álvarez 2009).

Las ECAS parten de la cultura rural campesina, que históricamente se ha pensado asimismo y ha construido una amalgama de propuestas de desarrollo endógeno que han partido desde el inquirir propio de ellas $y$ han permitido tener el control de los procesos que la afectan y la determinan; es decir, el control territorial, ecológico, social, cultural, económico y político (Toledo 2003). Además, en la sociedad rural campesina la solidaridad, la reciprocidad, la complementariedad, la fraternidad y la responsabilidad se amplía al mundo urbano a través de los mercados agroecológicos por la vida, donde en un intercambio de gestos, palabras y miradas las dos culturas se autoreconocen a sí mismas.

Así pues, Las ECAS parten de dos principios rectores; primero, que el saber individual se convierta en saber colectivo a través del diálogo de saberes en un territorio concretamente determinado (socializar el saber); segundo, que el saber acumulado colectivo se transmita de generación en generación; es decir, ser un mecanismo de transmisión de la herencia cultural y; convierta en el saber de todos. El saber recuperado, es un saber útil (sociabilizar el saber) (Castaño 2002). Estos principios van en contravía de la modernización acrítica que desconoce los saberes y 
experiencias locales, llamándolos supersticiosos, prejuiciosos, ingenuos, incompetentes; negando sistemáticamente una sabiduría y una cultura, construida durante milenios (Blandón 2002).

En estos lenguajes milenarios, largamente ignorados, desvalorizados o mal interpretados se encuentran las claves para remontar la actual crisis ecológica y socio-cultural desencadenada por la revolución industrial, la obsesión mercantil y el pensamiento racionalista.

De otro lado, los campesinos se volvieron dependientes y fueron encadenados a modelos de desarrollo modernizante, congelando lo que los había hecho autónomos y libertarios y, ahí la Universidad y los centros de experimentación cumpliendo su papel sistemático de negación de los conocimientos campesinos y garantes de la cientificidad exigida. El sector campesino implícita o explícitamente, es considerado, resistente al cambio, con aversión al riesgo, arcaico, irracional, primitivo, subdesarrollado, por lo tanto ignorante (Rengifo 1994).

Las ECAS recuperan, revalorizan, recrean y promocionan los saberes y culturas locales sobre los sistemas productivos y biodiversidad, recuperan formas de organización ancestral y re-establecen el diálogo con las deidades y la naturaleza. Trabajan en la propuesta agroecológica, con el diagnóstico y ordenamiento de las fincas y el territorio, buscan la seguridad y soberanía alimentaría de las familias y las comunidades, trabajan en procesos de recuperación, conservación y transformación de plantas medicinales, plantas ornamentales, medicinales, artesanales, alimenticias- yacón, sagú, achira, obambo, quinua, amarantos, tarwi, papas, maíz, frijol, entre otras. Es así, que las Escuelas se convierten por excelencia en el espacio para resarcir y reivindicar la vida rural.

Las ECAS la conforman entre 10 a 15 familias no diferenciando la participación de la esposa, el esposo, los hijos, los jóvenes, que comparten saberes y conocimientos. Trabajan en mingas cada
15 días y cambian manos entre los miembros con el fin de mejorar las parcelas y hacer posible la finca soñada. La escuela campesina se organiza a partir de la familia, la finca o chacra, la minga, la comunidad, la microcuenca, el centro de formación campesino o la federación campesina.

Ahora bien, para el funcionamiento adecuado de la escuela se designan entre los miembros los siguientes oficios o cargos, que cada año se rotan:

-El aguador: miembro encargado de cuidar el agua y los nacimientos tanto de la vereda como de las fincas de los campesinos miembros de la Escuela.

-El pacho: nombrado en rememoración a la $\mathrm{Pa}$ chamama; es el campesino encargado de velar por el cuidado del suelo.

-Duendes, cuenteros o historiadores: recopilan, sistematizan y transmiten la cultura de los campesinos. Es la memoria viviente de la comunidad, es "el narrador deja en él su huella, como la mano del alfarero sobre el vaso de arcilla”.

-Custodios: compañero que cuida las semillas y el pie de cría de los animales locales con quienes se establece una relación de reciprocidad a base de la cual cada una resulta beneficiada; es a quien se le entregan las semillas para que la reproduzca y las devuelva de nuevo a los socios de la Escuela. Convertirse en "custodio de semillas", significa respetar y proteger al germen que inicia la nueva vida.

-El curioso: En el mundo rural campesino existen campesinos cuya vocación por estar probando es manifiesta. Una curiosidad que debe ser apreciada como una suerte de ritual cotidiano de conversación con la naturaleza en la búsqueda de lo diverso (Rengifo 1994). El curioso es el encargado de llevar a cabo el plan de tanteo o prueba de la Escuela.

- La yerbatera: es la campesina (o) encargada de recoger y sistematizar el saber de las plantas medicinales y reflexionar sobre el uso de las hierbas con fines medicinales, humanos y animales.

- El Chabarí: en lengua Emberá Katío significa el hermano amigo, el compañero, el solidario 
que está dispuesto no solo a compartir las alegrías, sino también las tristezas.

De otro lado, las escuelas presentan diferentes grupos al interior de ellas, entre estos tenemos:

-Grupo de mujeres: las mujeres trabajan lo alimentario y el manejo de las plantas medicinales para el cuidado de la salud. Generan propuestas para transformar artesanalmente las plantas medicinales en productos de primera necesidad para la familia (Champú, jabón, pomadas, talcos, entre otros).

-Grupo de jóvenes y niños: trabajan la recuperación y sistematización de los saberes en un diálogo abierto con los mayores. Los jóvenes son los encargados del manejo del Centro de Formación Campesino.

- Grupo de Testimonio: a través de este grupo se fortalecen y sustentan los lazos de solidaridad, fraternidad, responsabilidad y confianza entre los productores y consumidores que asisten semanalmente al mercado agroecológico.

\section{Desarrollo Endógeno Sustentable en la búsqueda del "Vivir Bien"}

El desarrollo endógeno significa, desarrollo desde el inquirir propio de las comunidades locales -endógeno quiere decir "crecer desde adentro"para ello, el desarrollo endógeno se basa en la gestión de los propios recursos, estrategias e iniciativas propias, así como en la aplicación de conocimientos y sabidurías campesinas en el proceso de desarrollo. Estas soluciones desarrolladas a nivel popular incluyen las dimensiones materiales, socioculturales, así como espirituales, y se basan tanto en sistemas monetarios como no monetarios. Las acciones para el desarrollo endógeno es basado sobre necesidades y capacidades locales, a fin de ampliar las opciones disponibles para la gente, sin idealizar sus visiones y prácticas locales (Tapia 2008).

Según (Haverkort 2005) el desarrollo endógeno es definido como "desarrollo desde adentro", o desarrollo basado sobre iniciativas, conocimiento, instituciones y recursos locales. Las dinámicas del Desarrollo Endógeno no se pueden entender sin limitar el análisis a nivel local. Las influencias de otras culturas pertenecen a las principales fuerzas impulsoras del cambio (Haverkort et al. 2003). Muchos potenciales y amenazas al desarrollo endógeno yacen en la interfase de los sistemas locales, nacionales e internacionales. Resulta importante entender estas relaciones de poder entre los diversos sistemas de conocimiento, a fin de definir las mejores opciones y estrategias para el desarrollo endógeno.

Ahora bien, el Desarrollo Endógeno se puede definir, igualmente, como "desarrollo desde adentro" o "desarrollo basado principalmente (aunque no de forma exclusiva) sobre estrategias, conocimiento y recursos locales". Es un proceso continuo de "curación", adaptación e innovación, comenzando desde el interior de la comunidad local. Un criterio clave para el desarrollo endógeno es el controlado por los actores locales. Tiene la intención de reforzar los recursos locales para el beneficio de las poblaciones, y reforzar la habilidad de integración de los elementos externos a las prácticas locales (Rist 2005).

El Desarrollo Endógeno Sustentable distingue seis tipos de recursos: recursos naturales, humanos, producidos, económicos y financieros, sociales y culturales y espirituales.

\section{Resultados}

La presente pesquisa permitió la elaboración de 25 diagnósticos y planificaciones agroecológicas de las pequeñas fincas campesinas de los socios de las ECAS. Lo cual se convirtió en el insumo fundamental para elaboración participativa de dos planes de trabajo de las organizaciones. Estos planes se convierten en la carta de navegación de las organizaciones para caminar en la búsqueda del vivir bien; pues, el DES lo entendemos en las ECAS como una interfase para llegar a esta búsqueda. En suma, el plan da cuenta de los problemas, soluciones, potencia- 
lidades, prioridades y estrategias en el manejo de los bienes naturales y la reproducción de la comunidad misma. Los planes consisten en propuestas para dar respuestas a las deficiencias encontradas en los diferentes mundos (social, espiritual y material) desde la visión del Desarrollo Endógeno Sustentable el "Vivir Bien".

Los Planes de Trabajo se componen de lo siguiente:

1- Plan de Producción y Conservación (plan de producción agrícola, plan de producción pecuario y plan de conservación)

2- Plan de Capacitación

3- Plan de Experimentación

4- Plan de Mercadeo y Comercialización

5- Plan de Mingas

\section{Plan de Trabajo de la Escuela Campesina de Agroecología de San Lorenzo}

Nombre de la Escuela: Escuela Campesina de Agroecología de San Lorenzo. ASOAGRO (Asociación de Agricultores Orgánicos de San Lorenzo)

Ubicación: vereda Maravelez, corregimiento de San Rafael

\section{Número de asociados: 14}

El plan de trabajo de la ECA de San Lorenzo se genera o surge del diagnóstico de las diferentes fincas de los miembros que pertenecen a la Escuela. Este plan contiene los siguientes planes:

\subsection{Plan de producción y conservación} (agrícola, pecuario, artesanal y transformación)

Este plan de divide en plan de producción agrícola, plan de producción pecuario y plan artesanal y de transformación.

\subsubsection{Plan de producción agrícola}

Implementar una producción agrícola que utilice de manera adecuada el suelo y utilice la mano de obra, priorizando la soberanía alimentaria de la comunidad campesina, la diversidad de los cultivos, la transformación y la oferta de productos al mercado. Este plan consiste en planear ¿Qué se va producir en cada finca? y ¿Cómo se va a producir? Por consecuencia se genera el insumo necesario para la elaboración de los planes de minga a realizar.

\section{Medios productivos}

La Escuela expresa la necesidad de disponer de más tierra, para incrementar sus planes productivos colectivos. Así mismo, la necesidad de créditos blandos que no afecten la economía de las familias por el pago de los intereses; acompañados de un fortalecimiento al fondo rotatorio. Además, se plantea el fortalecimiento de la propuesta organizativa.

\section{Soberanía alimentaria}

Implementación huertas caseras agroecológicas: cilantro, cimarrón, cebolla, tomate, perejil, remolacha, lechuga, pepino, entre otros.

Cultivos promisorios: sagú, yacón, achira, cúrcuma, mafafa, yautía, malanga, batata, chachafruto.

San Lorenzo históricamente ha sido considerado un gran productor de almidón de sagú. Al punto que se le llamo "la montaña del sagú". Existen familias con la tradición del proceso de producción y transformación del mismo.

Cultivos de pan-coger: maíz, fríjol, zapallo, yuca, habichuela y arveja.

\section{Proyectos productivos:}

Café orgánico

Plátano y banano orgánico

Caña panelera

Frutales (aguacate, guanábana y cítricos)

Cacao

Plantas medicinales

Cultivos de tubérculos y raíces (harinas y almidones)

Cultivos de lulo y tomate de árbol 


\subsubsection{Plan de producción pecuaria}

En este plan es importante resaltar el cuidado especial que deben recibir los animales "bienestar animal”, donde se garantice todas las condiciones de vida de los animales tales como: sanidad, reproducción, alimentación sana, movilidad, entre otros. Se deben priorizar las especies criollas que conforman la cultura campesina y calcular la capacidad de carga del agroecosistema.

\section{Soberanía alimentaria}

Crianza de aves: gallina criolla, patos, bimbos, codornices

Crianza de cerdos criollos: zungos, chanchitos

Piscicultura alternativa

Conejos y curíes

Cabras

Ganado criollo

\section{Proyectos productivos}

Proyecto productivo de gallina criolla

Proyecto productivo de cerdos

Proyecto productivo de peces

Proyecto productivo de conejos y curíes

Proyecto productivo de cabras

\subsubsection{Plan de artesanías y transformación}

Este plan tiene por objeto suplir necesidades básicas de consumo al interior de la finca y puede convertirse en una alternativa económica. Así mismo, evita la intermediación en procesos comerciales y genera valor agregado a los productos de la finca, diversificando la producción, tales como:

Producción de artesanías en guadua

Transformación de plantas medicinales: Champú, talcos, pomadas, cremas y aceites

Transformación de cárnicos

Transformación de lácteos

Banco de proteína y energéticos

Banco de algas y plantas acuáticas: buchón, lechuguita, azola, salvinia

Producción de concentrados

Producción de abonos y biopreparados

\subsubsection{Plan de conservación}

Una vez que se ha diagnosticado la situación de los bienes naturales y se ha elaborado el plan de manejo ${ }^{1}$ de los mismos, se hace necesario llevar a cabo unos planes básicos de conservación y cuidado de los bienes naturales.

Plan de conservación de suelos

Plan de conservación y manejo de aguas (recuperación, almacenamiento, purificación)

Plan de conservación de bio y agro biodiversidad (conuco de crianzas y viveros)

Plan de uso de energía local: bancos de leña, biodigestores, pequeñas centrales hidroeléctricas de manejo comunitario, energía solar, energía eólica, etc.

NOTA 1. En todos los planes la actividad será orientada desde la práctica de las mingas, por lo tanto, se requiere del plan de mingas que permite que el sueño de finca, planteado en la planificación y ordenamiento de la misma se haga realidad a través del trabajo colectivo, en el entendido que para los pueblos andinos trabajar significa "estar de fiesta" $y$, solamente se produce si estamos de buen corazón. Con el trabajo en mingas se posibilita la construcción del módulo de abonos, el conuco de crianzas, los proyectos productivos y de conservación.

NOTA 2. La ECA, tendrá un Fondo Rotatorio manejado por el tesorero con el fin de apoyar los proyectos productivos y un Fondo de Solidaridad con el objeto de ayudar a los miembros de la Escuela que estén en situaciones difíciles. Este último lo coordina el Chabarí.

\section{2 - Plan de capacitación}

En el proceso de diagnóstico encontramos vacios de conocimiento acerca de las diferentes propuestas a realizar en la finca y hacer realidad el sueño de finca. En este sentido, la ECA, realiza un plan de capacitación con el acompañamiento del técnico y promotor rural, que salga

1 / No se apela al término recursos naturales, pues es un término eminentemente economicista que conduce a pensar que todo lo que la madre tierra nos brinda es susceptible de convertirse en mercancía. Es así, que se propone hablar de bienes naturales o comunes, un concepto no solo asociado a las necesidades del ser humano, sino a sus derechos como ciudadano. 
de las entrañas de la organización. Este plan de capacitación plantea un diálogo de saberes, intra e inter cultural, enmarcado en la metodología de campesino a campesino.

El Plan de capacitación planteado para la Escuela es el siguiente:

Filosofía de las Escuelas Campesinas de Agroecología (asignación de oficios)

Investigación - Acción - Participación (IAP)

Metodología campesino a campesino

Diálogo intra e inter científico

Historia oral

Desarrollo endógeno sustentable para el "Vivir Bien”

Diagnóstico y planificación de fincas y territorio

Plan de manejo de los bienes naturales: manejo ecológico del suelo, prácticas de manejo y conservación de aguas, conocimiento, manejo, uso y conservación de la bio y agro biodiversidad Materia orgánica y elaboración de abonos Protección ecológica de los cultivos

Capacitación en proyectos productivos: café, plátano, banano, caña, cacao, lulo, tomate de árbol, horticultura, tubérculos y raíces

Capacitación procesos de transformación, deshidratados, almidones, harinas, aceites, esencias, concentrados, conservas, encurtidos

Capacitación sobre bancos de proteínas, energéticas y plantas acuáticas

Capacitación sobre especies menores, especies mayores, piscicultura y diferentes razas animales

Capacitación en manejo de guadua y artesanías Capacitación sobre mercadeo y comercialización

Capacitación sobre condiciones ambientales y salud

\subsection{Plan de experimentación}

Las ECAS, necesitan un plan de experimentación donde las innovaciones tecnológicas -llegadas desde afuera- sean objeto de análisis por parte de los campesinos en sus sistemas de cultivo y producción, para su posterior adopción y apropiación; una vez demuestren sus bondades ambientales, sociales, económicas, espirituales y culturales en el espacio local. Estos planes van articulados a un diseño experimental participativo y acompañados con el técnico, el curioso y promotor campesino:

Experimentos sobre cromatografía de suelos y abonos

Ensayos con indicadores biológicos y métodos alternativos de diagnóstico

Ensayos con diferentes tipos de abonos

Parcelas de escorrentía

Ensayos con biopreparados

Sistema de cultivo

NOTA 3. El encargado y responsable de adelantar el plan, es el curioso de la Escuela.

\subsection{Plan de mercadeo y comercialización}

Este plan trabaja con los excedentes de los planes de producción, una vez la comunidad ha solventado su soberanía alimentaria. La comercialización evita la participación de los intermediarios, fortaleciendo la relación productor consumidor, al mismo tiempo que disminuye los costos de mercadeo:

Participación en mesas de acuerdo con ligas de consumidores reflexivos y solidarios

Fortalecimiento en la participación en el mercado agroecológico de Tuluá

Conformación del Grupo de Testimonio para la certificación de confianza

-Acuerdos y convenios con otras Escuelas y Grupos para comercializar en conjunto

NOTA 4. El responsable del plan de trabajo en general es el coordinador de la Escuela, para ello se construirá un plan de monitoreo y seguimiento.

\section{Plan de trabajo de la Escuela Cam- pesina de Agroecología de San Rafael}

Nombre de la Escuela: Escuela Campesina de Agroecología de San Rafael

Ubicación: Corregimiento de San Rafael

Número de Asociados: 12 
El plan de trabajo de la ECA de San Rafael se genera o surge del diagnóstico de las diferentes fincas de los miembros que pertenecen a la Escuela. Este plan contiene los siguientes planes:

\subsection{Plan de producción y conservación} (agrícola, pecuario, artesanal y transformación)

Este plan de divide en plan de producción agrícola, plan de producción pecuario y plan artesanal y de transformación.

\subsubsection{Plan de producción agrícola}

Implementar una producción agrícola que utilice de manera adecuada el suelo y utilice la mano de obra, priorizando la soberanía alimentaria de la comunidad campesina, la diversidad de los cultivos, la transformación y la oferta de productos al mercado. Este plan consiste en planear ¿Qué se va producir en cada finca? y ¿Cómo se va a producir? Por consecuencia se genera el insumo necesario para los procesos de los planes de minga a realizar.

\section{Medios productivos}

La Escuela expresa la necesidad de disponer de más tierra, para incrementar sus planes productivos colectivamente. Así mismo, la necesidad de créditos blandos que no afecten la economía de las familias por el pago de los intereses. Además, el fortalecimiento de la ECA.

\section{Soberanía alimentaria}

Implementación huertas caseras: cilantro, cimarrón, cebolla, tomate, perejil, Remolacha, lechuga, pepino, entre otros.

Cultivos promisorios: sagú, yacón, achira, cúrcuma, mafafa, yautía, malanga,

batata, chachafruto.

Cultivos de pan-coger: maíz, fríjol, zapallo, yuca, habichuela y arveja.

Proyectos productivos:

Café orgánico

Plátano y banano orgánico

Caña panelera

Frutales (aguacate, guanábana y cítricos)

Cacao
Plantas medicinales

Cultivos de tubérculos y raíces (harinas y almidones)

Cultivos de lulo y tomate de árbol

\subsubsection{Plan de Producción Pecuaria}

En este plan es importante resaltar el cuidado especial que deben recibir los animales "bienestar animal", donde se garantice, todas las condiciones de vida de los animales tales como: sanidad, reproducción, alimentación sana, movilidad, entre otros. Se deben priorizar las especies criollas que conforman la cultura campesina y calcular la capacidad de carga del agroecosistema.

\section{Soberanía alimentaria}

Crianza de aves: gallina criolla, patos, bimbos, codornices.

Crianza de cerdos criollos: zungos, chanchitos.

Piscicultura alternativa

Conejos y curíes

Cabras

Ganado criollo

\section{Proyectos productivos.}

Proyecto productivo de gallina criolla

Proyecto productivo de cerdos

Proyecto productivo de peces

Proyecto productivo de conejos y curíes

Proyecto productivo de cabras

\subsubsection{Plan de artesanías y transformación}

Este plan tiene por objeto suplir necesidades básicas de consumo al interior de la finca y puede convertirse en una alternativa económica. Así mismo, evita la intermediación en procesos comerciales y genera valor agregado a los productos de la finca, diversificando la producción, tales como:

Producción de artesanías en guadua y calceta de plátano.

Transformación de plantas medicinales: Champú, talcos, pomadas, cremas y aceites

Transformación de cárnicos.

Transformación del café

Transformación de la caña: panelas aromatiza- 
das-dulces

Transformación de lácteos

Banco de proteína y energéticos

Banco de algas y plantas acuáticas: buchón, lechuguita, azola, salvinia, etc.

Producción de concentrados

Producción de abonos y biopreparados

\subsubsection{Plan de conservación}

Una vez que se ha diagnosticado la situación de los bienes naturales y se ha elaborado el plan de manejo de los mismos, se hace necesario llevar a cabo unos planes básicos de conservación y cuidado de los bienes naturales.

Plan de conservación de suelos

Plan de conservación y manejo de aguas: recuperación, almacenamiento, purificación

Plan de conservación de bio y agrobiodiversidad: conuco de crianzas y viveros

Plan de uso de energía local, bancos de leña, biodigestores, pequeñas centrales hidroeléctricas de manejo comunitario, energía solar, energía eólica, etc.

NOTA 1. En todos los planes la actividad será orientada desde la práctica de las mingas, por lo tanto, se requiere del plan de mingas para posibilitar que el sueño de finca, planteado en la planificación y ordenamiento de la misma, se haga realidad a través del trabajo colectivo, en el entendido que para los pueblos andinos trabajar significa "estar de fiesta" y solamente se produce si estamos de buen corazón. Con el trabajo en mingas se posibilita la construcción del módulo de abonos, el conuco de crianzas, los proyectos productivos y de conservación.

NOTA 2. La ECA o el GO, tendrá un Fondo Rotatorio manejado por el tesorero con el fin de apoyar los proyectos productivos y, un Fondo de Solidaridad con el objeto de ayudar a los miembros de la Escuela que estén en situaciones difíciles. Este último lo coordina el Chabarí.

\subsection{Plan de capacitación}

En el proceso de diagnóstico encontramos vacíos de conocimiento acerca de las diferentes propuestas ha realizar en la finca y hacer realidad la finca soñada. En este sentido, la Escuela realiza un plan de capacitación con el acompañamiento del técnico y promotor rural, que salga de las entrañas de la organización. Este plan de capacitación plantea un diálogo de saberes, intra e inter cultural, enmarcado en la metodología de campesino a campesino.

El plan de capacitación planteado para la Escuela es el siguiente:

Filosofía de las Escuelas Campesinas de Agroecología (asignación de oficios) Investigación - Acción - Participación (IAP)

Metodología Campesino a Campesino

Diálogo intra e inter científico

Historia oral

Desarrollo endógeno sustentable para el "Vivir Bien”

Diagnóstico y planificación de fincas y territorio

Plan de manejo de los bienes naturales (manejo ecológico del suelo, prácticas de manejo y conservación de aguas, conocimiento, manejo, uso y conservación de la bio y agro biodiversidad) Materia orgánica y elaboración de abonos

Protección ecológica de los cultivos

Capacitación en proyectos productivos: café, plátano, banano, caña, cacao, lulo, tomate de árbol, horticultura, tubérculos y raíces

Capacitación procesos de transformación, deshidratados, almidones, harinas, aceites, esencias, concentrados, conservas, encurtidos, etc. Capacitación sobre bancos de proteínas, energéticas y plantas acuáticas

Capacitación sobre especies menores, especies mayores, piscicultura y diferentes razas animales

Capacitación en manejo de guadua y artesanías Capacitación sobre condiciones ambientales y salud

\subsection{Plan de experimentación}

Las ECAS, necesitan un plan de experimentación donde las innovaciones tecnológicas sean objeto de análisis por parte de los campesinos para su posterior apropiación, una vez demostradas las bondades en los sistemas de cultivos. 
Estos planes van articulados a un diseño experimental participativo, y acompañados con el técnico, el curioso y promotor campesino: Experimentos sobre cromatografía de suelos y abonos

Ensayos con indicadores biológicos y métodos alternativos de diagnóstico

Ensayos con diferentes tipos de abonos

Parcelas de escorrentía

Ensayos con biopreparados

Respuestas de cultivos al manejo agroecológico

NOTA 3. El encargado y responsable de adelantar este plan, es el curioso de la Escuela.

\subsection{Plan de mercadeo y comercialización}

Este plan trabaja con los excedentes de los planes de producción, una vez la comunidad ha solventado su soberanía alimentaria. La comercialización evita la participación de los intermediarios, fortaleciendo la relación productor consumidor, al mismo tiempo que disminuye los costos de mercadeo.

Participación en mesas de acuerdo con ligas de consumidores reflexivos y solidarios: cooperativas, sindicatos, ligas de usuarios.

Fortalecimiento en la participación en el mercado agroecológico de Tuluá

Conformación y capacitación del Grupo de Testimonio Campesino para generar la certificación de confianza.

Acuerdos y convenios con otras Escuelas y Grupos para comercializar en conjunto.

NOTA 4. El responsable del plan de trabajo en general es el coordinador de la Escuela, para ello se construirá un plan de monitoreo y seguimiento.

\section{Literatura citada}

AGRUCO. 1998. Plataforma para el diálogo intercultural sobre cosmovisión y agricultura. Plural Editores, La Paz.

Álvarez, F. 2009. Escuelas campesinas de agroecología una estrategia de desarrollo endógeno sus- tentable en los Andes tulueños. Informe Final Trabajo Especialización en Agroecología Tropical Andina. Corporación Universitaria Santa Rosa de Cabal, Santa Rosa de Cabal.

Blandón, G. 2002. Escuelas agroecológicas: una experiencia de desarrollo participativo. En: metodologías participativas hacia el diálogo de saberes. MAELA, Cochabamba. pp. 41-44.

Castaño, G. 2002-2003. Una experiencia de desarrollo rural humano sustentable en el departamento del Quindío, Corporación Campesina para el Desarrollo Sustentable- Surcos Comunitarios. En: Cátedra Ambiental, Memorias 20022003. CRQ Armenia. pp. 23-46.

Delgado, F. \& N. Tapia. 2005. Revitalizando el conocimiento indígena para el desarrollo endógeno. COMPAS, 7: 34-37.

Haverkort, B. 2005. Diagnóstico comunal en el desarrollo endógeno: lidiando con diferencias de poder. COMPAS, 7: 8-10.

Haverkort, B., K. Van't Hooft \& W. Hiemstra. (Eds.). 2003. Antiguas raíces, nuevos retoños: el desarrollo endógeno en la práctica. : COMPAS; Editores Plural; AGRUCO, La Paz. pp. 338.

Mejía, E. 1996. Origen del campesino vallecaucano: siglo XVIII y Siglo XIX. Universidad del Valle, Cali.

Rengifo, G. 1994. Experimentación campesina. Cuadernos de Trabajo No. 1. CECTEC, Asunción.

Rist, S. 2005. Desarrollo endógeno como un proceso social. COMPAS, 7: 26-29.

San Martín, J. 1997. Uk’amäpi: en la búsqueda del enfoque para el desarrollo rural autosostenible. Plural Editores; AGRUCO, La Paz.

Tapia, N. 2008. Aprendiendo el desarrollo endógeno sostenible: construyendo la diversidad biocultural. Serie cosmovisión y ciencia No. 3 . COMPAS Latinoamérica; AGRUCO; Plural Editores, La Paz.

Toledo, V. 2003. Ecología, espiritualidad y conocimiento de la sociedad del riesgo a la sociedad sustentable. Universidad Iberoamericana; PNUMA; Grupo Editorial Formato, México.

Toledo, V. 1991. El juego de la supervivencia: un manual para la investigación etnoecológica en Latinoamérica. Consorcio Latinoamericano sobre Agroecología y Desarrollo (CLADES); Centro de Ecología; Universidad Nacional Autónoma de México, Berkeley. p. 75.

Vásquez, E. 1996. Panorama histórico de la econo- 
mía vallecaucana en el siglo XX. 2a ed. Universidad del Valle; Instituto de Estudios del Pacífico, Cali. pp. 197-208.

Valencia, C. \& J. Londoño. 1996. El movimiento campesino en el Valle del Cauca. En: Valencia
L., A. (Ed.). Historia del Gran Cauca. Historia Regional del Suroccidente Colombiano. Centro de Estudios Regionales; Instituto de Estudios del Pacífico; Fundación General de Apoyo de la Universidad del Valle, Cali, pp. 179-184.

Recibido: 17 de agosto de 2010 Aceptado: 22 de noviembre de 2010 